\title{
Fecundity of the Atlantic Mackerel (Scomber scombrus) in the Northwest Atlantic in 1987
}

\author{
Carolyn A. Griswold \\ National Marine Fisheries Service, Northeast Fisheries Science Center ${ }^{*}$ \\ Narragansett Laboratory, Narragansett, RI 02882, USA \\ and \\ Myron J. Silverman \\ National Marine Fisheries Service, Northeast Fisheries Science Center* \\ Sandy Hook Laboratory, Highlands, NJ 07732, USA
}

\begin{abstract}
Fecundity estimates of Atlantic mackerel (Scomber scombrus) were derived from fish collected in 1987 off the coast of USA and Canada from two spawning contingents in the Northwest Atlantic. Estimates for females of 310 to $446 \mathrm{~mm}$ fork length in USA waters ranged from 155900 to 1643600 eggs. Fecundities for fish between 313 and $435 \mathrm{~mm}$ fork length in Canadian waters ranged from 208500 to 1548400 eggs. The 5- and 6-year-old fish were dominant in both locations. Fecundity was related to fork length, somatic weight and age in both spawning contingents. Fecundity estimates for the individual females in USA waters were lower than those in previously published results, while estimates for both the 1987 USA and Canadian contingents were higher than those reported previously for Canadian waters and a North Sea area.
\end{abstract}

\section{Introduction}

The Atlantic mackerel (Scomber scombrus Linnaeus) is a migratory species ranging from North Carolina (Sette, 1950) to Labrador (Parsons, 1970) in the Northwest Atlantic. It is widely distributed in the eastern North Atlantic as well (Wheeler, 1969). Since the early nineteenth century numerous fluctuations in catch have been associated with natural shifts in population abundance as well as changes in fishing effort (Anderson and Paciorkowski, 1980). The existence of northern and southern spawning contingents of the Northwest Atlantic population has been well documented by Sette (1950), Parsons and Moores (1974), Moores et al. (1975) and Ware (1977), but no one has demonstrated stock differentiation. The southern contingent ranging from North Carolina to Massachusetts spawns from mid-April to June (Berrien, 1978). The northern component spawns in the Gulf of St. Lawrence from the end of May to mid-August (Ware, 1977).

During the 1987 spawning season the Northeast Fisheries Center of the National Marine Fisheries Service, USA, in cooperation with scientists from the Polish Sea Fisheries Institute and the Canadian Department of Fisheries and Oceans, undertook a study to estimate the abundance of adult Atlantic mackerel in the western North Atlantic from Cape Hatteras to the Gulf of St. Lawrence through a series of ichthyoplankton surveys designed to estimate egg production. This paper describes results of a parallel fecundity study of Atlantic mackerel collected from both the northern and southern spawning contingents to support the calculations of adult abundance. Fecundity results are compared with those of some similar previous studies in the western North Atlantic and the North Sea.

\section{Methods}

A total of 295 Atlantic mackerel were examined for fecundity. Of these, 169 pairs of ovaries were from fish captured in USA waters and 126 from Canadian waters. Samples were collected from various areas off the coast of USA from 15 April to 10 May 1987 (Fig. 1) from the Polish trawlers Kulbin and Admiral Arciszewski using midwater trawls. Additional samples were obtained from USA commercial trawlers and party boats using bottom trawl and hook and line, respectively. Canadian samples were obtained from trap fisheries off Cape Breton, Nova Scotia, between 6 April and 10 June, 1987 (Fig. 1). All fish were randomly collected and kept frozen until examined. Each fish was sexed, measured to the nearest $1.0 \mathrm{~mm}$ for fork length $(F L)$ and total length (TL), and weighed to the nearest $0.1 \mathrm{~g}$ for somatic weight (SW), the weight after the ovaries and viscera were removed. Each pair of ovaries that were well developed as defined by Morse (1980) were extracted and preserved separately using $10 \%$ buffered formalin. Otoliths were extracted from all females used in the fecundity estimates and analyzed

\footnotetext{
* Formerly Northeast Fisheries Center.
} 


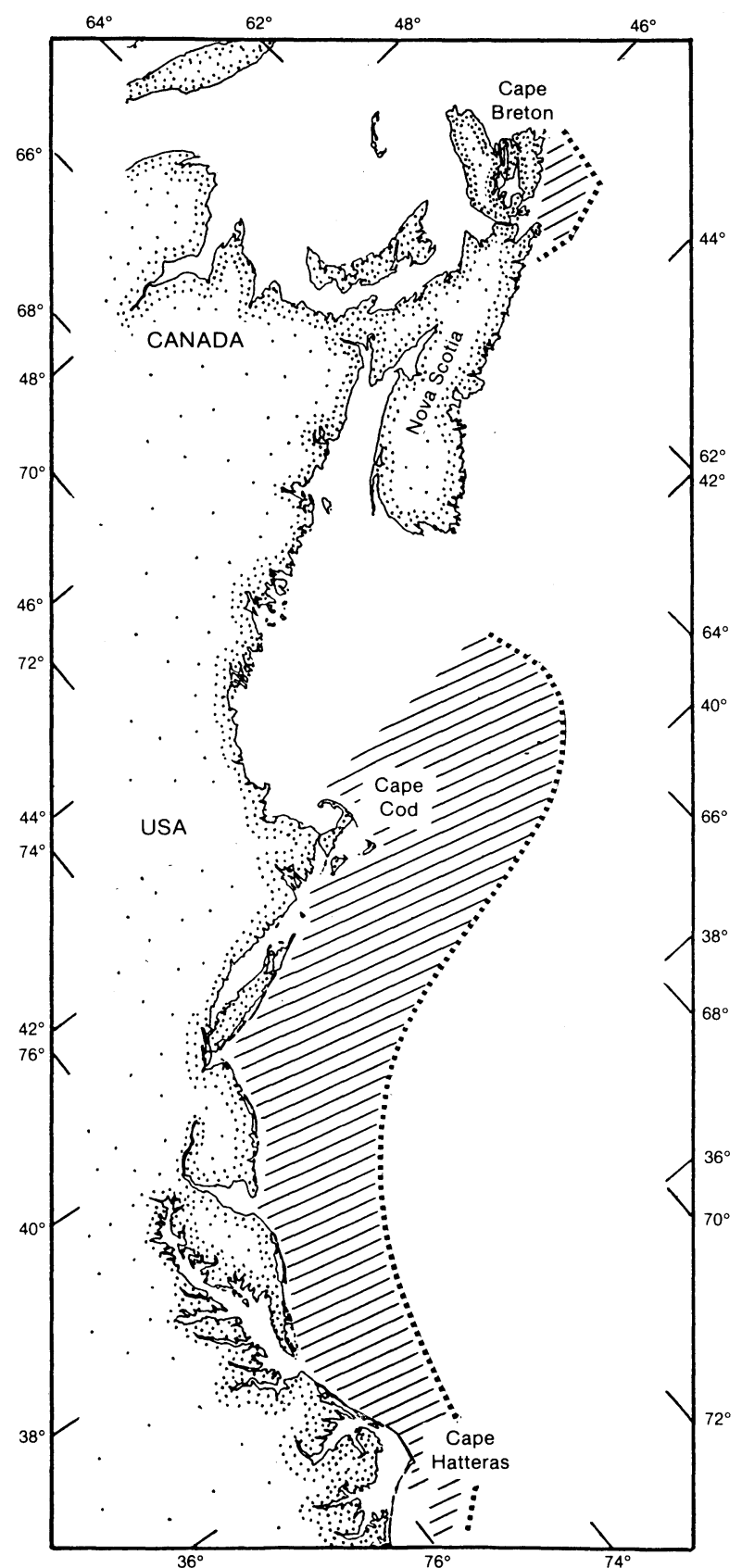

Fig. 1. The two regions in which Atlantic mackerel were collected for this study (crosshatched).

for age at the National Marine Fisheries Service, Woods Hole Laboratory, Woods Hole, Massachusetts, USA, according to the method of Dery (1988).

The ovaries were kept in the buffered formalin for at least 2 weeks to harden the ova (eggs). If translucent eggs were found in the lumen of a preserved ovary, that ovary was not used in the study as spawning may have commenced and eggs probably had been released. Ovaries were rinsed under running water and the eggs were separated gently from the matrix material by hand and collected using a $0.20 \mathrm{~mm}$ mesh sieve. Ovarian tissue was removed by hand and the eggs were airdried on absorbent paper for approximately 5-10 min. The total egg mass was placed in a plastic tray and weighed to the nearest $0.01 \mathrm{~g}$. Two aggregate subsamples, each containing several hundred eggs, were taken from the randomly clustered eggs and weighed to the nearest $0.001 \mathrm{~g}$. Eggs in the subsample were set in agar in a standard petri dish and counted using a binocular microscope. If the total number of eggs per unit weight in the subsamples differed by more than $10 \%$, an additional subsample was taken and the two subsamples which were within $10 \%$ of each other were used in the fecundity calculation. Seven percent of the 295 ovaries used in this study required an additional subsample. The total egg number was calculated based on the average number of eggs in the two subsamples and the total weight of the eggs in both ovaries.

\section{Results}

Fecundity ranged from 155900 to 1643600 eggs/ female for fish sampled in USA waters with fork lengths from 310 to $446 \mathrm{~mm}$ (Fig. 2). The fish age ranged from 3 to 14 years with the ages 5 and 6 years making up $55 \%$ (37 and 18\%, respectively) of the ripe females. For fish

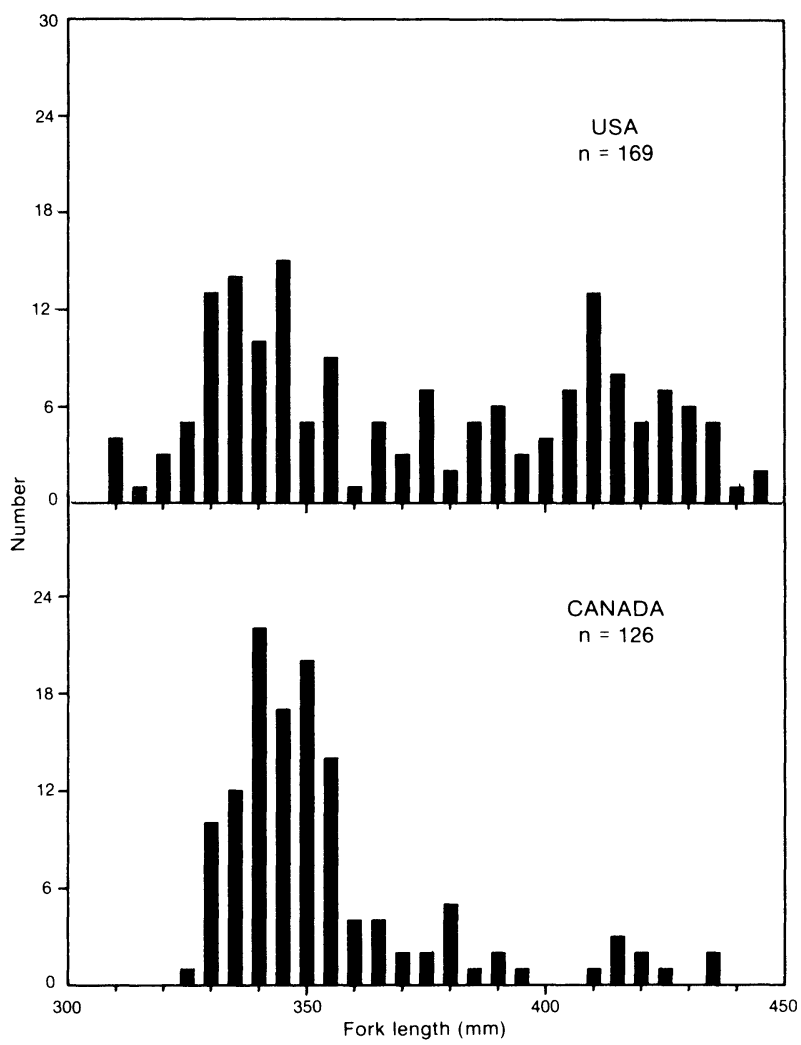

Fig. 2. The length-frequencies ( $5.0 \mathrm{~mm}$ groups) for the 1987 USA and Canadian samples of Atlantic mackerel females used in the fecundity estimates. 
sampled in Canadian waters with 313 to $435 \mathrm{~mm}$ FL (Fig. 2) and ages from 3 to 13 years, the fecundity was 208500 to 1548400 eggs. In the Canadian fish samples, $90 \%$ were 5 and 6 years old (77 and 13\%, respectively). The USA fish samples had more representatives that were older, although several year-classes were not represented in either set of samples (Fig. 3).

Plots of fecundity versus age, FL and SW, as well as coefficients of the logarithmic regressions, are presented in Fig. 3-5 for both groups of fish. Fecunditylength relationships that we determined are compared to those found by Morse (1980) for the 1977 USA contingent, Walsh (MS 1983) for 1982 from the North Sea, and Pelletier (1986) for 1982-85 from the Gulf of St. Lawrence in Fig. 6 and the accompanying regression equations are listed in Table 1. All length measurements were converted to standard units of $\mathrm{mm}$ and numbers to thousands of eggs. In order to use Walsh's data in these comparisons, his equation relating Fecundity to TL was converted to a Fecundity-FL relationship. Walsh's original equation was stated as:

$$
F=0.00311 * T L^{3.169}
$$

We converted this to the form of the other fecundity equations, to obtain:

$$
\log F=-2.507+3.169(\log T L)
$$

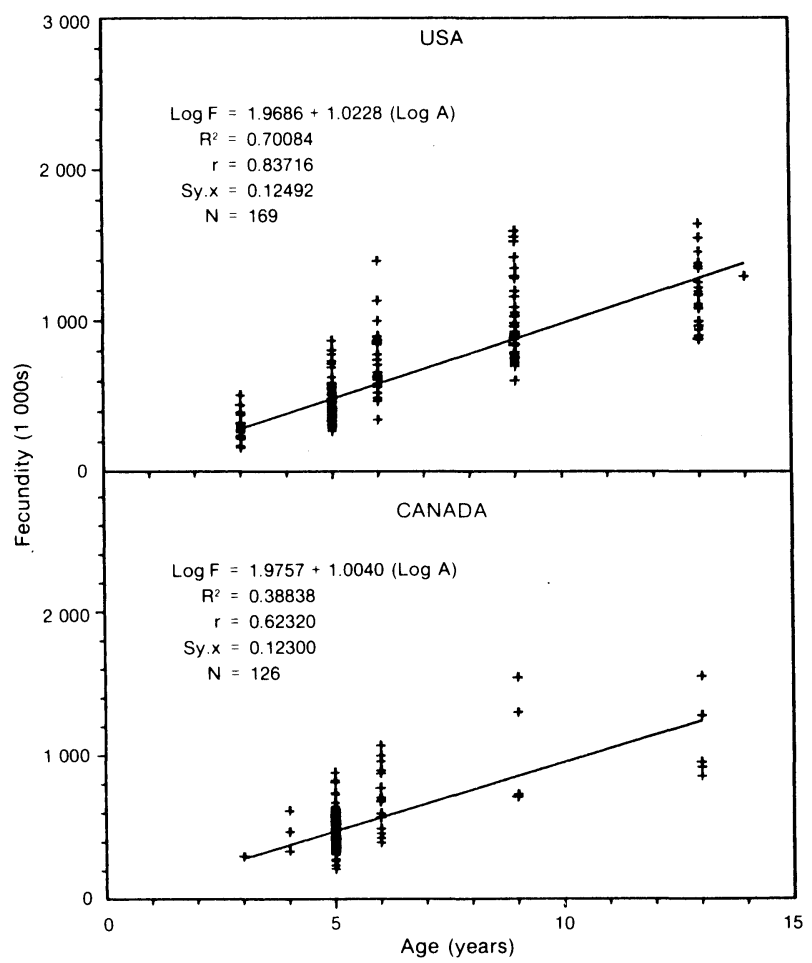

Fig. 3. The relationship of fecundity and age, and the predictive logarithmic (base 10) regression, for the USA and Canadian Atlantic mackerel samples in 1987.

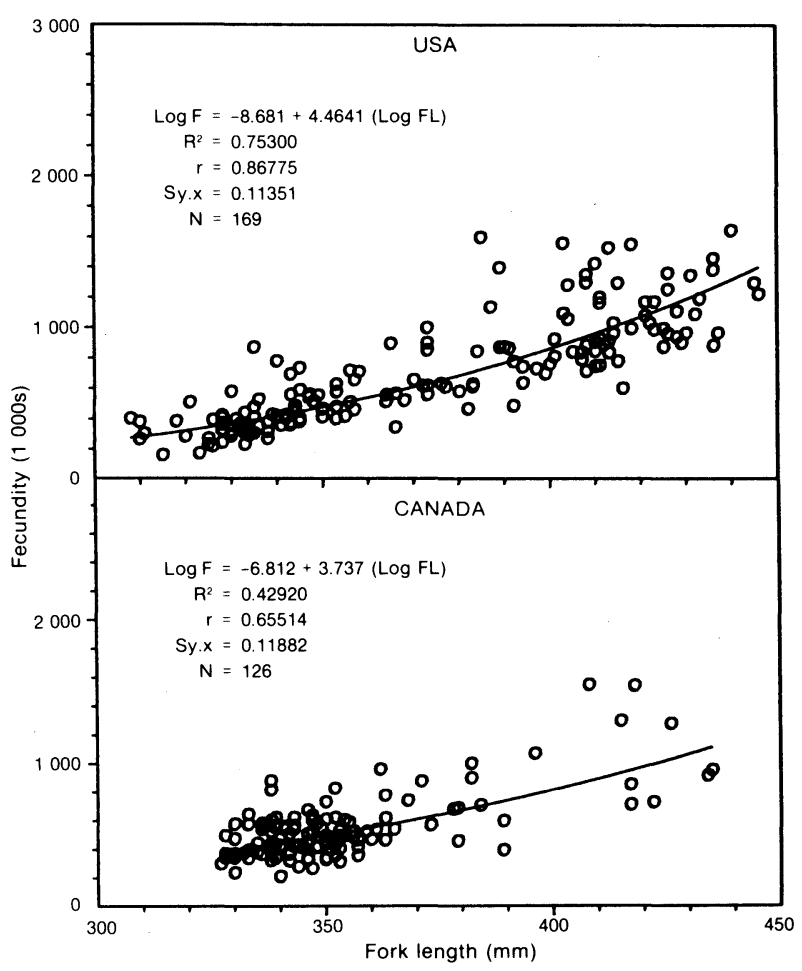

Fig. 4. The relationship of fecundity and fork length, and the predictive logarithmic (base 10) regression, for the USA and Canadian Atlantic mackerel samples in 1987.

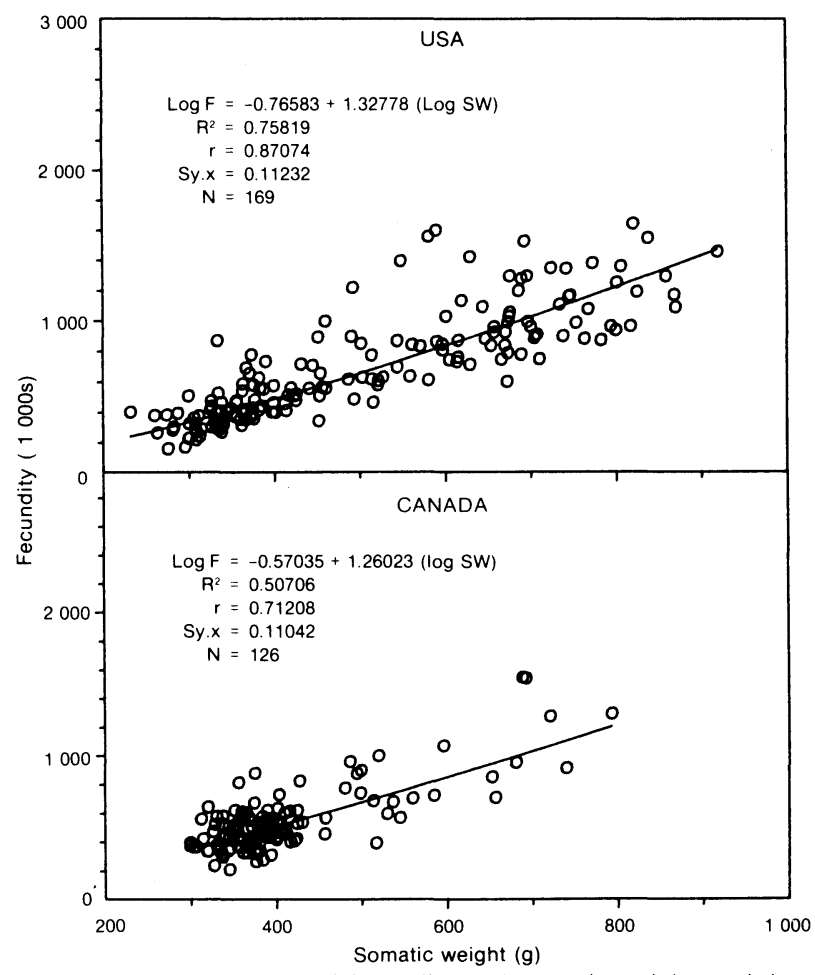

Fig. 5. The relationship of fecundity and somatic weight, and the predictive logarithmic (base 10) regression, for the USA and Canadian Atlantic mackerel samples in 1987. 
Using the TL:FL ratio from all fish measured in this study, we derived the following relationship whereby we could convert TL to FL:

$$
T L=1.09985 * F L
$$

where $n=295$, standard error of the slope (Sy.x) $=$ 0.00065 , and $r=>0.999$. Using this relationship, we transformed Walsh's equation to:

$\log F=-2.376+3.169(\log F L)$ in eggs, or

$\log F=-5.376+3.169(\log F L)$ in thousands of eggs, the form presented in Table 1.
A Student's t-test was used to compare the slopes of the regressions for the 1987 USA and Canadian data and for the Morse (1980) 1977 data on the USA contingent. Only the slopes of the fecundity-age regressions for the 1987 USA and Canadian spawning contingents were not different at the 0.05 level (Table 2). A t-test on the intercept of fecundity versus age failed to reject the hypothesis that both intercepts are the same, as well. The t-test also was used to compare the 1987 USA, the North Sea (Walsh, MS 1983) and Gulf of St. Lawrence (Pelletier, 1986) fecundity-length relationships, the only relationships for which sufficient data were

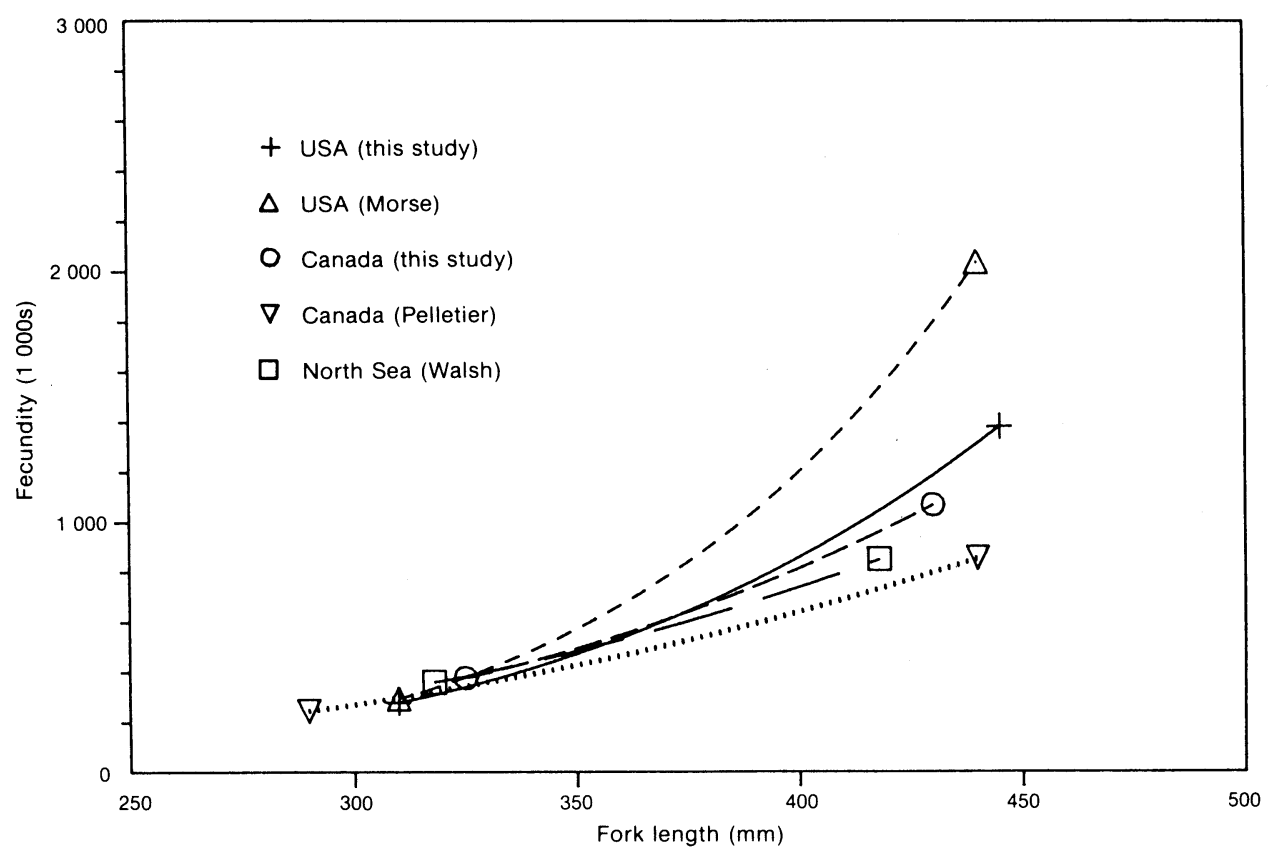

Fig. 6. Fecundity-length relationships for the Atlantic mackerel off the coast of USA (this study; Morse, 1980), the Canadian coast (this study; Pelletier, 1986), and in the North Sea (Walsh, MS 1983).

TABLE 1. Fecundity-length regressions for several Atlantic mackerel populations.

\begin{tabular}{|c|c|c|c|}
\hline Source & Sample & Year & Fecundity-length ${ }^{\mathrm{a}}$ regressions \\
\hline This study & USA & 1987 & $\begin{array}{l}\log F=-8.681+4.464(\log F L) \\
r=0.87 \quad N=169 \\
\text { Sy.x }=0.11351\end{array}$ \\
\hline This study & Canada & 1987 & $\begin{array}{l}\log F=-6.812+3.737(\log F L) \\
r=0.66 \quad N=126 \\
\text { Sy.x }=0.11882\end{array}$ \\
\hline Morse (1980) & USA & 1977 & $\begin{array}{l}\log F=-11.346+5.544(\log F L) \\
r=0.88 \quad N=218 \\
\text { Sy.x }=0.066\end{array}$ \\
\hline Pelletier (1986) & Canada & $1982-85$ & $\begin{array}{l}\log F=-5.050+3.02(\log F L) \\
r=0.56 \quad N=214\end{array}$ \\
\hline Walsh (MS 1983) & North Sea & 1982 & $\begin{array}{l}\log F=-5.376+3.169(\log F L) \\
r=0.52 \quad N=64 \\
\text { Sy.x }=0.508\end{array}$ \\
\hline
\end{tabular}

all regressions are expressed in $\mathrm{mm}$ and thousands of eggs. 
TABLE 2. The results of the Student's t-test which was used to compare the slopes of the regressions for fecundity versus fork length, somatic weight, or age of the 1987 samples from USA waters, with the same regressions for the 1987 Canadian samples and the Morse (1980) data and with the fecundity versus fork length regressions of Walsh (MS 1983) and Pelletier (1986).

\begin{tabular}{lrrr}
\hline \hline $\begin{array}{l}\text { United States } \\
\text { versus }\end{array}$ & $\begin{array}{r}\text { Fork } \\
\text { length }\end{array}$ & $\begin{array}{c}\text { Somatic } \\
\text { weight }\end{array}$ & \multicolumn{1}{c}{ Age } \\
\hline Canada & 53.066 & 5.132 & $1.290^{\mathrm{a}}$ \\
Morse (1980) & 110.170 & 21.435 & 16.151 \\
Walsh (MS 1983) $^{\mathrm{b}}$ & 20.204 & & \\
Pelletier (1986) & 12.721 & & \\
\hline
\end{tabular}

a The only comparison which was not rejected at the 0.05 level.

b Walsh used TL, but our conversion between TL and FL had a standard error of 0.00065 ; thus the Walsh standard error is unchanged by the conversion so the test is valid.

c Pelletier did not present data for the standard error of the slope (Sy.x), so the test was against a constant and thus considered to be a weaker test

reported. In each case the slopes of the regressions tested were significantly different at the 0.05 level, indicating that the fecundity-length relationships of the populations compared differed significantly by area and year (Table 2).

\section{Discussion}

As expected, fecundity for both spawning contingents of Atlantic mackerel increased with an increase in length, weight and age, although there was considerable variation within and between the two groups. Fecundity was slightly higher in the Canadian samples for fish smaller than $370 \mathrm{~mm}$ and $600 \mathrm{~g}$. At that size, the regressions crossed and for larger fish, the fecundities were higher in USA waters. No significant differences occurred at age between the two groups. Fecundity for the 1987 populations was lower than those observed by Morse (1980) for the 1977 contingent, but higher than previous studies of fish from Canadian waters (Pelletier, 1986) and those taken from North Sea waters (Walsh, MS 1983) (Fig. 6).

A possible explanation for the higher fecundity of mackerel in USA waters in 1977 than in 1987 could be that fecundity is inversely related to stock size (Overholtz et al., 1988). Stock estimates of the Atlantic mackerel in 1977 for the Northwest Atlantic as a whole indicated abundance to be the lowest in a decade, whereas by 1987 stocks had increased to the high levels of the early-1970s (Conservation and Utilization Division, 1989). (It has not yet been proven possible to separate the two contingents for stock assessment purposes.) When stocks were low in 1977, fish grew more rapidly, matured earlier and had higher fecundity at length (Morse, 1980) than the 1987 stocks where fish of the same age were smaller and had lower fecundity at length (Table 1, Fig. 6).
Atlantic mackerel stocks were just beginning to rebuild between 1982 and 1985 and continued to increase through 1987 (Conservation and Utilization Division, 1989) so it is difficult to explain, using the above criteria, why fecundity-at-length estimates for Canadian waters in 1982-85 by Pelletier (1986) were lower than ours for 1987. One explanation might be the differences in techniques of subsampling the eggs. Pelletier (1986) and Walsh (MS 1983) used the volumetric sampling method, while in this study and in Morse (1980), the gravimetric method was used in which the eggs were air dried and a subsample removed. Walsh (1983) emphasized that different methods used to estimate fecundity can give widely varying results.

These comparisons within and among spawning contingents in different years illustrate that spawning potential of Atlantic mackerel may change with changes in total stock size, as well as with population size composition and age structure. Fecundity estimations should be conducted annually in conjunction with concurrent population dynamics studies in order to assess trends in spawning potential associated with natural fluctuations.

\section{Acknowledgements}

We are grateful to $M$. Castónguay and K. Zwanenburg for providing us with the Canadian fish samples. Doris Finan, Alice Wells, Donna Johnson, Ellen Johnson and Susan O'Connor helped with the samples. Sue Koelb developed the data management system, and Ruth Briggs entered all data. We appreciate Wally Morse and Bill Overholtz's review; we also thank Wally Smith and Jack Green for reviewing the manuscript and for their continued support. We are particularly grateful to Julien Goulet whose help, patience and suggestions were invaluable.

\section{References}

ANDERSON, E. D., and A. J. PACIORKOWSKI. 1980. A review of the Northwest Atlantic mackerel fishery. ICES Rapp. Proc.-Verb., 177: 175-211.

BERRIEN, P. L. 1978. Eggs and larvae of Scomber scombrus and Scomber japonicus in continental shelf waters between Massachusetts and Florida. Fish. Bull. U.S., 76: 95-115.

CONSERVATION AND UTILIZATION DIVISION. 1989. Status of the fisheries resources off the northwestern United States for 1989. NOAA Tech. Mem., NMFS-F/NEC-72, $110 \mathrm{p}$.

DERY, L. M. 1988. Atlantic herring Clupea harengus. In: Age determination methods for Northwest Atlantic species. J. Pentilla and L. Dery (eds.). NOAA Tech. Rep., NMFS 72: 17-22.

MOORES, J. A., G. H. WINTERS, and L. S. PARSONS. 1975. 
Migrations and biological characteristics of Atlantic mackerel (Scomber scombrus) occurring in Newfoundland waters. J. Fish. Res. Board Can., 32: 1347-1357.

MORSE, W. W. 1980. Spawning and fecundity of Atlantic mackerel, Scomber scombrus, in the middle-Atlantic Bight. Fish. Bull. U.S., 78: 103-108.

OVERHOLTZ, W. J., S. A. MURAWSKI, W. L. MICHAELS, and L. M. DERY. 1988. The effects of density dependent population mechanisms on assessment advice for the Northwest Atlantic mackerel stock. NOAA Tech. Mem., NMFS-F/NEC-62, $49 \mathrm{p}$.

PARSONS, L. S. 1970. Northern range extension of the Atlantic mackerel, Scomber scombrus, to Black Island, Labrador. J. Fish. Res. Board Can., 27: 610-613.

PARSONS, L. S., and J. A. MOORES. 1974. Long distance migration of an Atlantic mackerel (Scomber scombrus). J.
Fish. Res. Board Can., 31: 1521-1522.

PELLETIER, L. 1986. Fécondité du maquereau bleu, Scomber scombrus L., du golfe du Saint-Laurent. Rapport technique canadien des sciences halieutiques et aquatiques. No. 1467: 1-37.

SETTE, O. E. 1950. Biology of the Atlantic mackerel (Scomber scombrus) of North America. Part II: Migrations and habits. U.S. Fish. Wildl. Serv., Fish. Bull. U.S., 51: 251-258.

WALSH, M. MS 1983. Investigations on the fecundity of North Sea mackerel. ICES C.M. Doc., No. H:48, 10 p.

WARE, D. M. 1977. Spawning time and egg size of Atlantic mackerel, Scomber scombrus, in relation to the plankton. J. Fish. Res. Board Can., 34: 2308-2315.

WHEELER, A. 1969. The fishes of the British Isles and NorthWest Europe. Michigan State Univ. Press, East Lansing, $613 \mathrm{p}$. 